\title{
Biomarkers of Kidney Injury in Very-low-birth-weight Preterm Infants: Influence of Maternal and Neonatal Factors
}

\author{
IRENE CAPELLI $^{1}$, FRANCESCA VITALI $^{2}$, FULVIA ZAPPULO $^{1}$, SILVIA MARTINI $^{2}$, CHIARA DONADEI $^{1}$, \\ MARIA CAPPUCCILLI ${ }^{1}$, LUCA LEONARDI ${ }^{3}$, ANNA GIRARDI ${ }^{3}$, VALERIA AIELLO ${ }^{1}$, SILVIA GALLETTI $^{2}$, \\ GIACOMO FALDELLA ${ }^{2}$, ELISABETTA POLUZZI ${ }^{3}$, FABRIZIO DE PONTI $^{3}$ and LA MANNA GAETANO ${ }^{1}$ \\ ${ }^{1}$ Department of Experimental Diagnostic and Specialty Medicine (DIMES), Nephrology, \\ Dialysis and Renal Transplant Unit, St. Orsola-Malpighi University Hospital, \\ University of Bologna, Bologna, Italy; \\ ${ }^{2}$ Department of Medical and Surgical Sciences, Neonatal Intensive Care Unit, \\ St. Orsola-Malpighi University Hospital, University of Bologna, Bologna, Italy; \\ ${ }^{3}$ Department of Medical and Surgical Sciences, Pharmacology Unit, University of Bologna, Bologna, Italy
}

\begin{abstract}
Background/Aim: Acute kidney injury is an important cause of mortality in very-low-birth-weight (VLBW) preterm infants. As in the general population, the detection of renal damage cannot rely on the measurement of serum creatinine, since it has been demonstrated to be a weak predictor and a delayed indicator of kidney function deterioration. However, several candidate biomarkers have failed to prove sufficient specificity and sensitivity for a routine clinical use because of the poor awareness of their biological role. This study was aimed to investigate the impact of different maternal and neonatal conditions on several renal biomarkers in VLBW preterm infants during the first week of life. Patients and Methods: Preterm infants $<32$ weeks' gestation and $<1500 \mathrm{~g}$ were enrolled. We measured urinary biomarkers kidney injury molecule 1 (KIM-1), neutrophil gelatinase-associated lipocalin $(N G A L)$, cystatin $C$, epidermal growth factor $(E G F)$ and osteopontin $(O P N)$ on the $1^{\text {st }}, 3^{\text {rd }}$, and $7^{\text {th }}$ day after birth. Results: Thirty-tree infants were included. The multivariate analysis showed a significant association between gestational age, the presence of patent ductus arteriosus, antenatal maternal hypertension and the levels of urinary biomarkers. Conclusion:
\end{abstract}

This article is freely accessible online.

Correspondence to: Gaetano La Manna, MD, Ph.D., Department of Experimental, Diagnostic and Specialty Medicine (DIMES) Nephrology, Dialysis and Transplantation Unit, St. Orsola Hospital, University of Bologna, Via G. Massarenti 9 (Pad. 15), 40138 Bologna, Italy. Tel: +39 0512144577, Fax: +39 051344439, e-mail: gaetano.lamanna@unibo.it

Key Words: Gestational age, kidney injury biomarkers, maternal hypertension, patent ductus arteriosus, very-low-birth-weight preterm infants.
There is a possible relation between early biomarkers of renal injury and antenatal, perinatal and post-natal characteristics in $V L B W$ preterm infants during the first week of life.

Preterm birth is burdened by high rates of perinatal morbidity and mortality worldwide (1). With an estimated incidence of $12-18 \%$, acute kidney injury (AKI) is among the main causes of mortality in the preterm population, and represents an independent predictor of mortality even after adjustment for confounding variables, namely comorbidities, interventions and demographic characteristics $(2,3)$. Preterm birth is also associated with an increased risk of cardiovascular and chronic kidney disease in adulthood; this poses important challenges for the clinicians to detect as soon as possible developmental and functional abnormalities that could affect lifetime $(4,5)$.

In humans and experimental animals, however, measurable changes in serum creatinine and glomerular filtration rates can be evident only after a remarkable reduction in kidney function (less than $50-80 \%$ of normal values), being thus insensitive to detect subclinical renal damage. Moreover, serum creatinine levels can be influenced by several factors, such as gender, age, hydration state, muscle mass, ongoing medications and endogenous metabolites (e.g., bilirubin) $(3,6)$.

In the neonatal population, AKI definitions based on serum creatinine are susceptible to specific additional limitations: in the first days of life, serum creatinine may reflect the maternal kidney function $(7,8)$ and it is not able to distinguish pre-renal injuries, which are often reversible and transient, from intrinsic renal injuries (9). Moreover, serum creatinine does not provide specific information on the type of kidney insult (e.g., toxic, infectious, ischemic etc.). Hence, several biomarkers other than serum creatinine have been investigated to allow a timely diagnosis of AKI, to localize the site of injury and to predict nephrotoxicity (10). Kidney injury molecule 1 (KIM-1), 
neutrophil-gelatinase-associated lipocain (NGAL), interleukin 18 (IL-18), cystatin C, clusterin, fatty acid binding protein-liver type (L-FABP) and osteopontin (OPN) are among the most promising biomarkers proposed for early AKI diagnosis and, in the neonatal population, have the additional benefit of being detected in urine samples, which can be collected non-invasively. In preterm infants, urinary NGAL and epidermal growth factor (EGF) have been shown to predict AKI onset several hours before the rise in serum creatinine (11). However, many candidate biomarkers, taken as single standalone molecules, have failed to prove sufficient specificity and sensitivity for a routine clinical use: this is most likely due to the poor understanding of their biological role (12). Moreover, as for serum creatinine, several conditions may influence its concentration. In adult cohorts, increased urinary and plasmatic NGAL levels have been correlated with the severity of the illness in patients suffering from acute renal failure, but also from other clinical conditions (sepsis, infectious disease, multiple organ failure), and a significant association with mortality rates has been reported (13, 14). Elevated NGAL levels were also found in children with urinary infections (15). Moreover, previous evidence indicated that conditions implying cellular necrosis or apoptosis, such as ischemia or infections, can up-regulate the synthesis of NGAL in different organs (liver, lung and kidney) (16). To date, only few biomarkers have been evaluated in the preterm neonatal population to assess renal function and possibly identify infants at higher risk of AKI. In two nested case-control studies, Askenazi et al. explored the individual and combined predictive value of six different urinary biomarkers on AKI and mortality in 123 VLBW infants, observing significantly higher levels of NGAL and OPN in neonates with AKI, and significantly higher OPN and KIM-1 concentrations in non-survivors compared to survivors (17).

In the preterm population, gestational age (GA), birth weight, postnatal age and gender have been reported to significantly affect urine renal biomarkers $(18,19)$. Hence, in order to contribute to the validation of renal biomarkers for AKI diagnosis in preterm infants, it is crucial to understand the possible role of different antenatal and perinatal factors on their concentration.

This study aimed to investigate the impact of different maternal and neonatal conditions on the changes in kidney injury molecule 1 (KIM-1), neutrophil gelatinase-associated lipocalin (NGAL), cystatin C, epidermal growth factor (EGF) and osteopontin (OPN) as candidate urinary biomarkers of kidney function in VLBW preterm infants during the first week of life.

\section{Patients and Methods}

Patients. Infants born at S. Orsola-Malpighi University Hospital, Bologna (Italy) hospital from September 2016 to June 2017 and admitted to the local Neonatal Intensive Care Unit were included in this prospective, observational study if fulfilling the following criteria: GA $\leq 32$ weeks and birth weight $<1,500 \mathrm{~g}$. Congenital anomalies of kidney and urinary tract (CAKUT) were exclusion criteria. Infants who died within the first $48 \mathrm{~h}$ of life or who developed AKI, defined as an increase in serum creatinine $(\mathrm{sCr}) \geq 0.3 \mathrm{mg} / \mathrm{dl}$ by $48 \mathrm{~h}$ or $\geq 1.5$ times baseline or urine output below $0.5 \mathrm{ml} / \mathrm{kg} / \mathrm{h}$ for at least $6 \mathrm{~h}(20)$ during the study period were also excluded.

For each infant, the following data were recorded: history of maternal hypertension $(\mathrm{MH})$ prior to delivery as defined by American College of Obstetricians and Gynecologists (21), antenatal evidence of abnormal umbilical flow at Doppler evaluation, maternal chorioamnionitis, GA, birth weight, Apgar score at 1' and 5' (22), clinical risk index for babies II (CRIB II) score (23), gender, twin birth, echocardiographic evidence of an hemodynamically significant patent ductus arteriosus (PDA) over the first week of life, development of medical and/or surgical necrotizing enterocolitis (24) and/or sepsis (defined by clinical signs and symptoms and positive blood culture or C-reactive protein $\geq 2.5 \mathrm{mg} / \mathrm{dl}$ ) and need for antibiotics for $\geq 5$ days) (25) during the study period.

The study was approved by the local Ethical Committee (protocol n. 154/2015/U/Oss, BIOPREA-2016) and written informed consent was obtained from the parents or legal carers of the infants.

Assays. Blood and urinary samples were collected on day 1 (T0), day 3 (T1) and day 7 (T2) from the enrolled newborns. Serum creatinine levels (sCr) were determined at the Central Laboratory of our hospital by routine biochemistry methods. Urine specimens were obtained by aspiration from the diaper, and then assayed for urinary biomarkers at the Laboratory of Nephrology, Dialysis and Renal Transplant Unit of the same hospital. Urinary analytes were measured by multiplex methods for simultaneous quantification of different molecules through Luminex MAGPIX technology (Luminex, Austin, TX, USA), and data were analyzed using the Analyst 5.1 PLUS software (Millipore). Three sessions were carried out to determine: (a) NGAL, cystatin C, EGF and OPN; (b) UMOD; (c) calbindin, clusterin, GST- $\pi$, IL-18, KIM-1, and MCP-1. The abovementioned urinary biomarkers were assayed using the commercially available kits (MILLIPLEX MAP Human Kidney Injury Magnetic Bead Panel 1 \#HKI1MAG-99K and Human Kidney Injury Magnetic Bead Panel 2 \#HKI2MAG-99K, Millipore Corp., Billerica, MA; Bio-Plex Pro $^{\text {TM }}$ RBM Human Kidney Toxicity Assays, Bio-Rad Laboratories, Segrate, Italy). The concentrations were calculated using a standard curve through serial dilutions. For the aim of the study, only KIM-1, NGAL, cystatin C, EGF and OPN were analyzed. The sensitivity limits (minimum detectable concentrations) were $0.014 \mathrm{ng} / \mathrm{ml}$ for KIM-1, $0.01 \mathrm{ng} / \mathrm{ml}$ for NGAL, $0.16 \mathrm{ng} / \mathrm{ml}$ for cystatin $\mathrm{C}, 0.02 \mathrm{ng} / \mathrm{ml}$ for EGF and $0.40 \mathrm{ng} / \mathrm{ml}$ for OPN. The coefficients of variation (CV\%) were: $<10 \%$ intra-assay and $<15 \%$ interassay for KIM-1, NGAL and OPN; $<10 \%$ intra-assay and $<20 \%$ interassay for cystatin $\mathrm{C} ;<10 \%$ intra-assay and $<10 \%$ inter-assay for EGF.

Statistical analysis. The distribution of renal biomarkers was determined by means of Shapiro-Wilk test. Since these parameters followed a normal distribution, differences over time (T0, T1 and T2) in the renal biomarkers were evaluated by one-way ANOVA. Student's $t$-test was used to compare renal biomarkers at T0, T1 and T2 in relation to different maternal and neonatal variables. A multiple linear regression model, including AKI biomarkers at different time points as dependent variables and the factors that resulted statistically significant at the univariate analysis as independent variables, was built to evaluate the independent effect of each variable on the observed results. The significance level was set at $p<0.05$. All the analyses were conducted using IBM SPSS, version 25.0 (SPSS Inc., Chicago, IL, USA). 
Table I. Clinical characteristics of the study population.

\begin{tabular}{|c|c|}
\hline Clinical characteristics & $\mathrm{N}=32$ \\
\hline $\begin{array}{l}\text { Gestational age (weeks), median } \\
\text { (interquartile range, IQR) }\end{array}$ & $29(26.5-30)$ \\
\hline Birth weight (g), median (IQR) & $1092(826-1,363)$ \\
\hline \multicolumn{2}{|l|}{ Apgar score } \\
\hline 1', median (IQR) & $8(7-8)$ \\
\hline 5', median (IQR) & $9(9-9)$ \\
\hline \multicolumn{2}{|l|}{ CRIB II score } \\
\hline Level 1, n (\%) & $9(28.1)$ \\
\hline Level 2, n (\%) & $16(50)$ \\
\hline Level $3, \mathrm{n}(\%)$ & $7(21.9)$ \\
\hline Level 4, n (\%) & $0(0)$ \\
\hline Maternal age (years), median (IQR) & $36(31-39)$ \\
\hline Maternal hypertension, n (\%) & $7(21.9)$ \\
\hline \multicolumn{2}{|l|}{ Antenatal umbilical Doppler } \\
\hline Normal, n (\%) & $24(75)$ \\
\hline Absent or reversed end-diastolic flow, n (\%) & $8(25)$ \\
\hline \multicolumn{2}{|l|}{ Gender } \\
\hline Males, n (\%) & $24(75)$ \\
\hline Females, n (\%) & $8(25)$ \\
\hline \multicolumn{2}{|l|}{ Type of gestation } \\
\hline Twin, n (\%) & $13(59.4)$ \\
\hline Single, $\mathrm{n}(\%)$ & $19(40.6)$ \\
\hline \multicolumn{2}{|l|}{ Mode of delivery } \\
\hline Vaginal delivery, n (\%) & $5(16)$ \\
\hline Caesarean section, $\mathrm{n}(\%)$ & $27(84)$ \\
\hline \multicolumn{2}{|l|}{ Status of ductus arteriosus } \\
\hline Patent, hemodynamically significant, n (\%) & $11(34.4)$ \\
\hline Restrictive or closed, n (\%) & $22(65.6)$ \\
\hline
\end{tabular}

CRIB: Clinical risk index for babies.

\section{Results}

Thirty-three VLBW infants were enrolled in the study. The clinical characteristics of the study population are shown in Table I. Out of 8 infants with antenatal impairment of umbilical Doppler, 7 had a maternal history of hypertension prior to delivery.

Trends over time of sCr, KIM-1, NGAL, cystatin C, EGF and OPN are illustrated in Figure 1. No changes in $\mathrm{sCr}$ were observed from $\mathrm{T} 0$ to $\mathrm{T} 2$. Although not significant, a trend towards a decrease from $\mathrm{T} 0$ to $\mathrm{T} 2$ was found for cystatin $\mathrm{C}$ and KIM-1, whereas EGF and NGAL showed a slightly increased excretion at $\mathrm{T} 1$.

As shown in Table II, GA, PDA and antenatal MH were associated with significantly different levels of all the studied biomarkers at different time-points over the first week of life. Infants with GA below 30 weeks showed significantly increased levels of NGAL and cystatin $\mathrm{C}$ from $\mathrm{T} 0$ to $\mathrm{T} 2$ and higher $\mathrm{sCr}$ at $\mathrm{T} 1$ and $\mathrm{T} 2$, while no differences were observed for KIM-1 and EGF. Moreover, newborns with PDA displayed significantly higher values of $\mathrm{sCr}$ from $\mathrm{T} 0$ to $\mathrm{T} 2, \mathrm{KIM}-1$ at T0 and cystatin $\mathrm{C}, \mathrm{OPN}, \mathrm{NGAL}$ at $\mathrm{T} 2$. There were no significant differences between genders at any of the experimental times, apart from a tendency towards higher NGAL values in females at T0, T1 and T2. A history of antenatal MH was associated with a significant increase in serum creatinine at $\mathrm{T} 0$ and $\mathrm{T} 1$ and higher NGAL and cystatin C levels at T0.

Given the intrinsic association between MH, GA and PDA, a multiple linear regression model was developed to assess the independent effect of each variable at specific time points. According to the model, a significant effect of GA was also confirmed for $\mathrm{sCr}$ at $\mathrm{T} 1(\mathrm{~B}=0.145, p=0.020)$ and $\mathrm{T} 2(\mathrm{~B}=0.321$, $p=0.012)$, NGAL at T1 $(B=199.92, p=0.035)$, and cystatin $\mathrm{C}$ at T0 $(\mathrm{B}=144.62, p=0.004)$, whereas the presence of PDA was independently associated with a higher $\mathrm{sCr}$ at $\mathrm{T} 0(\mathrm{~B}=0.189$, $p=0.004)$. Moreover, a significant impact of antenatal $\mathrm{MH}$ on $\mathrm{sCr}$ at $\mathrm{T} 1(\mathrm{~B}=0.156, p=0.036)$ and on NGAL at $\mathrm{T} 0(\mathrm{~B}=182.45$, $p=0.014)$ and $\mathrm{T} 1(\mathrm{~B}=198.04, p=0.043)$ was confirmed.

No history of maternal chorioamnionitis was documented. Moreover, none of the enrolled infants had a CRIB II score $>15$, nor developed sepsis or necrotizing enterocolitis during the first week of life.

\section{Discussion}

According to our results, different neonatal and maternal factors can influence renal biomarkers in VLBW preterm neonates without AKI over the first week of life. In particular, GA, the presence of PDA and antenatal MH were significantly associated with the levels of $\mathrm{sCr}$, NGAL, and cystatin $\mathrm{C}$ at specific days after birth.

NGAL is certainly the most studied biomarker as an early predictor of AKI in several clinical settings, although data from preterm infants are still scanty. We have previously reported that renal function in VLBW infants is associated with urinary NGAL levels in the first 3 days of life (12). Similarly, Argyri et al. reviewed the possible diagnostic role of some promising biomarkers in the early diagnosis and prognosis of AKI in newborns (26). Indeed, how different pathophysiological factors or maternal and neonatal characteristics may affect the changes in these biomarkers has not been fully clarified yet. Here, we observed a significant inverse correlation between GA and NGAL concentration during the first week of life. Our data are thus consistent with the findings by Lavery et al. who found a negative association between NGAL and birth weight, which can be regarded as a proxy for GA (27). This GAdependency of NGAL values is feasibly due to the immature tubular function ensuing from preterm birth. The evidence of a progressive decline in urinary NGAL in preterm-born neonates over the first 3 months of life could reflect the progressive post-natal maturation of nephrogenesis, which is complete around 36 weeks post-conceptional age (28).

In a prospective cohort study, Saeidi et al. evaluated 14 urine biomarkers in 81 preterm infants without AKI, 

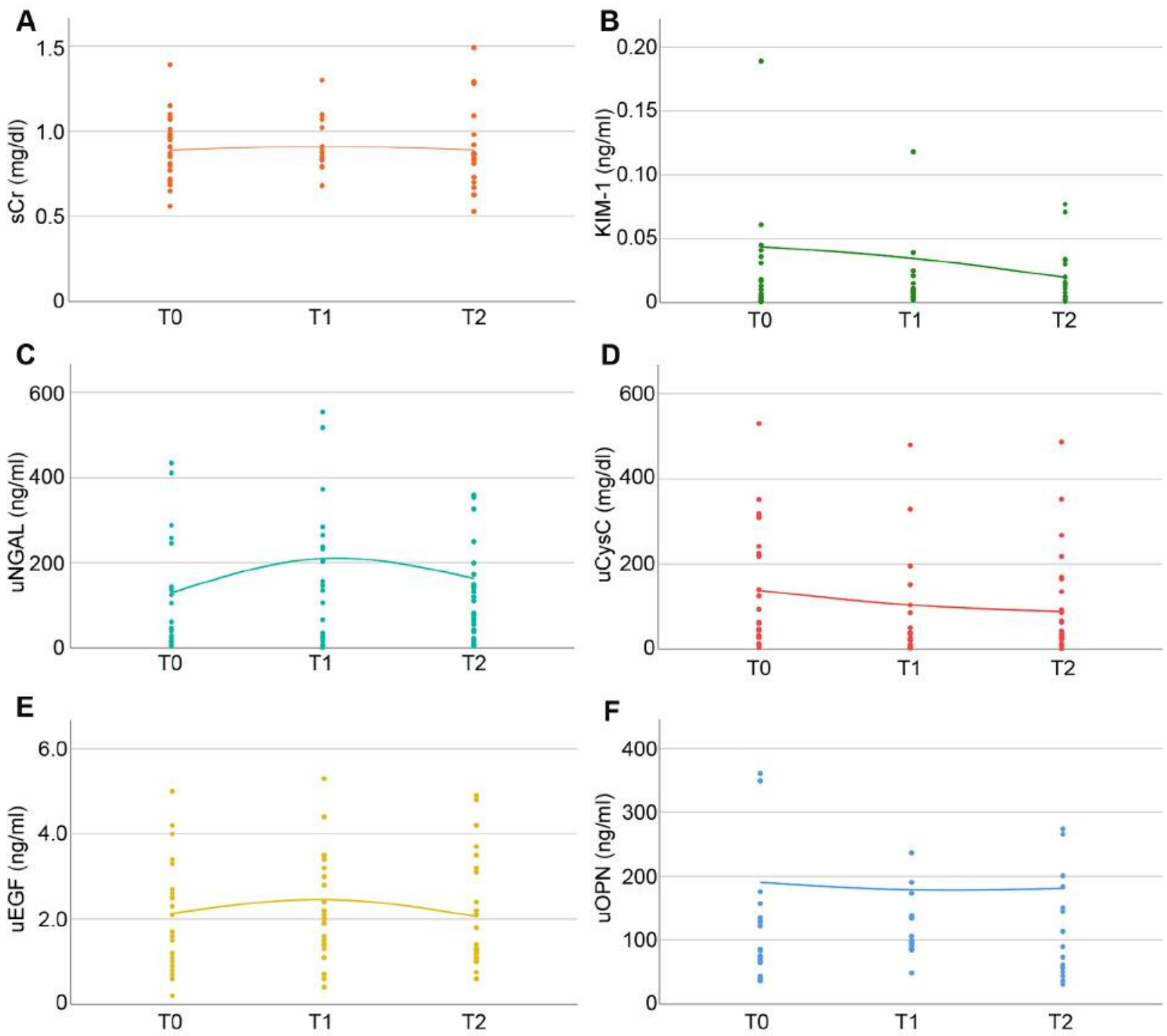

Figure 1. Levels of serum creatinine $(A)$ and urinary KIM-1 (B), NGAL $(C)$, cystatin $C(D), E G F(E)$ and $O P N(F)$ at TO (day 1$)$, T1 (day 3$)$ and T2 (day 7). EGF: Epidermal growth factor; KIM-1: kidney injury molecule 1; NGAL: neutrophil gelatinase-associated lipocalin; OPN: osteopontin; sCr: serum creatinine.

observing a significant association between the concentration of biomarkers (in particular, NGAL and cystatin C) and clinical variables as postnatal age, GA and gender (17). Consistently, DeFreitas et al. found a significant association between cystatin C and GA (29). The progressive decrease in urinary NGAL excretion observed over the first 4 days of life was not confirmed by our results.

Concerning PDA, up to now, only a few studies have evaluated its impact on renal biomarkers. Tosse et al. found higher uNGAL levels in 37 neonates with a birth weight below $1,500 \mathrm{~g}$ and with a PDA that needed either medical or surgical intervention, compared to matched controls with no PDA or a PDA requiring no intervention (30). In our cohort, the presence of PDA seemed to increase the levels of some biomarkers.
However, it should be recognized that 10 out of 11 neonates with evidence of PDA during the first week of life were treated with ibuprofen; hence, it was not possible to discriminate the effect of PDA from that of the related drug therapy on renal biomarkers.

More recently, Sellmer et al. evaluated the impact of PDA on a cohort of 146 neonates with GA below 32 weeks; after adjusting for GA and gender, no difference in relation to the PDA status was observed, thus suggesting that NGAL may not be influenced by PDA (31). In line with this study, in our infants we found a significant correlation between the levels of renal biomarkers and the presence of PDA at the univariate analysis, but this finding was not confirmed by the multivariate model, where the effects of other covariates (i.e., GA, MH) prevailed over PDA in determining NGAL concentration. 
Capelli et al: Kidney Injury Biomarkers in VLBW Preterm Infants

Table II. Between-group comparison of renal biomarkers at T0 (day 1), T1 (day 3) and T2 (day 7) in relation to the infants' gestational age, ductal status, history of maternal hypertension and gender.

\begin{tabular}{|c|c|c|c|c|c|c|c|c|}
\hline T0 & $\mathrm{GA}<30$ wks & $\mathrm{GA} \geq 30$ wks & PDA & No PDA & HM & NM & Males & Females \\
\hline $\mathrm{sCr}(\mathrm{mg} / \mathrm{dl})$ & $\begin{array}{c}0.95 \\
(0.79-0.99)\end{array}$ & $\begin{array}{c}0.82 \\
(0.71-0.91)\end{array}$ & $\begin{array}{c}0.98 * * \\
(0.96-1.04)\end{array}$ & $\begin{array}{c}0.78^{* *} \\
(0.71-0.87)\end{array}$ & $\begin{array}{c}0.98^{*} \\
(0.93-1.09)\end{array}$ & $\begin{array}{c}0.83^{*} \\
(0.72-0.96)\end{array}$ & $\begin{array}{c}0.90 \\
(0.74-0.97)\end{array}$ & $\begin{array}{c}0.91 \\
(0.79-1.01)\end{array}$ \\
\hline KIM-1 (ng/ml) & $\begin{array}{c}0.011 \\
(0.004-0.063)\end{array}$ & $\begin{array}{c}0.018 \\
(0.01-0.036)\end{array}$ & $\begin{array}{c}0.040 * \\
(0.008-0.103)\end{array}$ & $\begin{array}{c}0.01 * \\
(0.001-0.018)\end{array}$ & $\begin{array}{c}0.036 \\
(0.007-0.045)\end{array}$ & $\begin{array}{c}0.015 \\
(0.003-0.038)\end{array}$ & $\begin{array}{c}0.015 \\
(0.004-0.044)\end{array}$ & $\begin{array}{c}0.031 \\
(0.005-0.036)\end{array}$ \\
\hline NGAL (ng/ml) & $\begin{array}{c}136.1^{*} \\
(39.3-258.3)\end{array}$ & $\begin{array}{c}15.4^{*} \\
(7.7-39.2)\end{array}$ & $\begin{array}{c}124.6 \\
(39.3-245.7)\end{array}$ & $\begin{array}{c}35.5 \\
(12.9-117.2)\end{array}$ & $\begin{array}{c}249.3 * * \\
(115.1-515.9)\end{array}$ & $\begin{array}{c}69.1 * * \\
(37.6-142.7)\end{array}$ & $\begin{array}{c}33.7 \\
(15.7-137)\end{array}$ & $\begin{array}{c}133.7 \\
(57.1-318.4)\end{array}$ \\
\hline CysC (mg/dl) & $\begin{array}{c}218.1 * * \\
(62-310.3)\end{array}$ & $\begin{array}{c}29.4 * * \\
(15.9-32.8)\end{array}$ & $\begin{array}{c}224.6 \\
(62-308.6)\end{array}$ & $\begin{array}{c}44.1 \\
(30-127.9)\end{array}$ & $\begin{array}{c}241^{*} \\
(143.3-309.4)\end{array}$ & $\begin{array}{c}45.7^{*} \\
(30.6-128.5)\end{array}$ & $\begin{array}{c}60.4 \\
(30.7-178.8)\end{array}$ & $\begin{array}{c}143.7 \\
(37.1-312.1)\end{array}$ \\
\hline EGF (ng/ml) & $\begin{array}{c}2.1 \\
(1.1-2.5)\end{array}$ & $\begin{array}{c}2.1 \\
(1-3.1)\end{array}$ & $\begin{array}{c}2.1 \\
(1.7-3.4)\end{array}$ & $\begin{array}{c}1.65 \\
(1.02-2.57)\end{array}$ & $\begin{array}{c}2.3 \\
(2.1-2.4)\end{array}$ & $\begin{array}{c}1.65 \\
(0.97-2.85)\end{array}$ & $\begin{array}{c}2.1 \\
(1.2 .55)\end{array}$ & $\begin{array}{c}1.85 \\
(1.25-3.7)\end{array}$ \\
\hline OPN (ng/ml) & $\begin{array}{c}128.7 * \\
(84.4-392.7)\end{array}$ & $\begin{array}{c}65.3^{*} \\
(42.4-74.1)\end{array}$ & $\begin{array}{c}85.7 \\
(75-121.8)\end{array}$ & $\begin{array}{c}77.3 \\
(56.4-161.7)\end{array}$ & $\begin{array}{c}262.3 \\
(162.1-370.8)\end{array}$ & $\begin{array}{c}71.6 \\
(43-128.7)\end{array}$ & $\begin{array}{c}85.7 \\
(66.3-166.3)\end{array}$ & $\begin{array}{c}75 \\
(36.3-128.7)\end{array}$ \\
\hline $\mathrm{T} 1$ & $\mathrm{GA}<30$ wks & $\mathrm{GA} \geq 30$ wks & PDA & No PDA & $\mathrm{HM}$ & NM & Males & Females \\
\hline $\mathrm{sCr}(\mathrm{mg} / \mathrm{dl})$ & $\begin{array}{c}0.90^{*} \\
(0.86-1.07)\end{array}$ & $\begin{array}{c}0.81^{*} \\
(0.79-0.84)\end{array}$ & $\begin{array}{c}1.04 * \\
(0.89-1.09)\end{array}$ & $\begin{array}{c}0.84^{*} \\
(0.79-0.88)\end{array}$ & $\begin{array}{c}1.07 * \\
(1.02-1.1)\end{array}$ & $\begin{array}{c}0.85^{*} \\
(0.79-0.88)\end{array}$ & $\begin{array}{c}0.85 \\
(0.79-0.91)\end{array}$ & $\begin{array}{c}0.88 \\
(0.85-1.02)\end{array}$ \\
\hline KIM-1 (ng/ml) & $\begin{array}{c}0.009 \\
(0.007-0.016)\end{array}$ & $\begin{array}{c}0.011 \\
(0.004-0.025)\end{array}$ & $\begin{array}{c}0.01 \\
(0.008-0.021)\end{array}$ & $\begin{array}{c}0.009 \\
(0.006-0.026)\end{array}$ & $\begin{array}{c}0.01 \\
(0.003-0.013)\end{array}$ & $\begin{array}{c}0.011 \\
(0.007-0.027)\end{array}$ & $\begin{array}{c}0.013 \\
(0.008-0.029)\end{array}$ & $\begin{array}{c}0.006 \\
(0.003-0.008)\end{array}$ \\
\hline NGAL (ng/ml) & $\begin{array}{c}218.7 * \\
(143.2-413.1)\end{array}$ & $\begin{array}{l}23.2^{*} \\
(6-65.6)\end{array}$ & $\begin{array}{c}85.7 \\
(20-459.3)\end{array}$ & $\begin{array}{c}105.8 \\
(18.9-251)\end{array}$ & $\begin{array}{c}372.4^{*} \\
(118.4-590.8)\end{array}$ & $\begin{array}{c}120.3 * \\
(23.9-225.2)\end{array}$ & $\begin{array}{c}105.8 \\
(22.9-218.8)\end{array}$ & $\begin{array}{c}186.1 \\
(61.1-396.6)\end{array}$ \\
\hline CysC (mg/dl) & $\begin{array}{c}85.6 \\
(38.4-172.9)\end{array}$ & $\begin{array}{c}23.1 \\
(20.4-46.3)\end{array}$ & $\begin{array}{c}77.9 \\
(33.9-115.2)\end{array}$ & $\begin{array}{c}30.5 \\
(20.8-59.7)\end{array}$ & $\begin{array}{c}85.6 \\
(50-150.9)\end{array}$ & $\begin{array}{c}35.1 \\
(20.6-69.6)\end{array}$ & $\begin{array}{c}20.7 \\
(9.6-50.2)\end{array}$ & $\begin{array}{c}55.8 \\
(10.7-150.9)\end{array}$ \\
\hline EGF (ng/ml) & $\begin{array}{c}2.3 \\
(1.4-3.5)\end{array}$ & $\begin{array}{c}2 \\
(1.6-3.4)\end{array}$ & $\begin{array}{c}2.2 \\
(1.4-3)\end{array}$ & $\begin{array}{c}2.55 \\
(1.45-3.72)\end{array}$ & $\begin{array}{c}1.5 \\
(1.35-2.85)\end{array}$ & $\begin{array}{c}2.6 \\
(1.6-73.47)\end{array}$ & $\begin{array}{c}2.2 \\
(1.4-3.35)\end{array}$ & $\begin{array}{c}2.7 \\
(1.5-3.7)\end{array}$ \\
\hline OPN (ng/ml) & $\begin{array}{c}106.2 \\
(92.7-190.1)\end{array}$ & $\begin{array}{c}91.8 \\
(57.3-125.4)\end{array}$ & $\begin{array}{c}164.1 * \\
(100.6-224.9)\end{array}$ & $\begin{array}{c}96.2 * \\
(84.1-106.2)\end{array}$ & $\begin{array}{c}97.1 \\
(87.3-122.9)\end{array}$ & $\begin{array}{c}99.5 \\
(88.4-164.1)\end{array}$ & $\begin{array}{c}106.2 \\
(88.1-173.2)\end{array}$ & $\begin{array}{c}64.7 \\
(25-231.8)\end{array}$ \\
\hline $\mathrm{T} 2$ & $\mathrm{GA}<30 \mathrm{wks}$ & $\mathrm{GA} \geq 30$ wks & PDA & No PDA & $\mathrm{HM}$ & NM & Males & Females \\
\hline $\mathrm{sCr}(\mathrm{mg} / \mathrm{dl})$ & $\begin{array}{c}0.89 * \\
(0.85-1.13)\end{array}$ & $\begin{array}{c}0.67 * \\
(0.63-0.7)\end{array}$ & $\begin{array}{c}0.92^{*} \\
(0.86-1.21)\end{array}$ & $\begin{array}{c}0.77^{*} \\
(0.66-0.88)\end{array}$ & $\begin{array}{c}1.05 \\
(0.75-1.28)\end{array}$ & $\begin{array}{c}0.85 \\
(0.7-0.9)\end{array}$ & $\begin{array}{c}0.85 \\
(0.67-0.95)\end{array}$ & $\begin{array}{c}0.95 \\
(0.77-1.19)\end{array}$ \\
\hline CysC (mg/dl) & $\begin{array}{c}75.8^{*} \\
(35.6-167.6)\end{array}$ & $\begin{array}{c}26.9^{*} \\
(22.7-30)\end{array}$ & $\begin{array}{c}91.8^{*} \\
(38.3-193.2)\end{array}$ & $\begin{array}{c}30 * \\
(23-3-40)\end{array}$ & $\begin{array}{c}62.9 \\
(18.9-179.5)\end{array}$ & $\begin{array}{c}34.3 \\
(27.2-80.9)\end{array}$ & $\begin{array}{c}33.8 \\
(25.3-134.6)\end{array}$ & $\begin{array}{c}39.3 \\
(29.9-64.3)\end{array}$ \\
\hline KIM-1 (ng/ml) & $\begin{array}{c}0.006 \\
(0.004-0.013)\end{array}$ & $\begin{array}{c}0.016 \\
(0.007-0.029)\end{array}$ & $\begin{array}{c}0.008 \\
(0.013-0.016)\end{array}$ & $\begin{array}{c}0.005 \\
(0.005-0.023)\end{array}$ & $\begin{array}{c}0.011 \\
(0.005-0.016)\end{array}$ & $\begin{array}{c}0.008 \\
(0.005-0.017)\end{array}$ & $\begin{array}{c}0.013 \\
(0.005-0.024)\end{array}$ & $\begin{array}{c}0.003 \\
(0.002-0.005)\end{array}$ \\
\hline NGAL (ng/ml) & $\begin{array}{c}142.7 * \\
(81.6-326.1)\end{array}$ & $\begin{array}{c}42.6^{*} \\
(12.8-70.4)\end{array}$ & $\begin{array}{c}287.7 * * \\
(125.9-357.3)\end{array}$ & $\begin{array}{c}59.3 * * \\
(26.4-128.5)\end{array}$ & $\begin{array}{c}245.7 * * \\
(9.7-422.3)\end{array}$ & $\begin{array}{c}41.1 * * \\
(15.6-127.5)\end{array}$ & $\begin{array}{c}79.6 \\
(33.9-150.1)\end{array}$ & $\begin{array}{c}140.1 \\
(66.2-276.2)\end{array}$ \\
\hline EGF (ng/ml) & $\begin{array}{c}1.6 \\
(1.2-3.6)\end{array}$ & $\begin{array}{c}2.1 \\
(1.2-2.6)\end{array}$ & $\begin{array}{c}1.8 \\
(1.3-3.6)\end{array}$ & $\begin{array}{c}1.75 \\
(1.12-2.37)\end{array}$ & $\begin{array}{c}1.4 \\
(1.2-3.45)\end{array}$ & $\begin{array}{c}1.95 \\
(1.21-2.92)\end{array}$ & $\begin{array}{c}1.3 \\
(1.2-2.2)\end{array}$ & $\begin{array}{c}3.1 \\
(1.7-3.4)\end{array}$ \\
\hline OPN (ng/ml) & $\begin{array}{c}144.8 \\
(50.3-265.6)\end{array}$ & $\begin{array}{c}93.3 \\
(63.9-113-3)\end{array}$ & $\begin{array}{c}265.6^{* *} \\
(192-454.6)\end{array}$ & $\begin{array}{c}50.3 * * \\
(15.4-93.3)\end{array}$ & $\begin{array}{c}119.8 \\
(81.3-158.4)\end{array}$ & $\begin{array}{c}67 \\
(31.9-186.7)\end{array}$ & $\begin{array}{c}75.1 \\
(38.1-196.3)\end{array}$ & $\begin{array}{c}93.3 \\
(36.8-129.1)\end{array}$ \\
\hline
\end{tabular}

$* p<0.05 ; * *<<0.001$. CysC: Cystatin C; EGF: epidermal growth factor; GA: gestational age; HM: hypertensive mother; KIM-1: kidney injury molecule 1; NGAL: neutrophil gelatinase-associated lipocalin; NM: normotensive mother; OPN: osteopontin; PDA: patent ductus arteriosus; sCreat: serum creatinine; T0: post-natal day 1; T1: post-natal day 3; T2: post-natal day 7 .

Besides, we observed significantly higher levels of urinary NGAL during the first 3 days of life in case of antenatal history of $\mathrm{MH}$; this finding was confirmed even after adjustment for other covariates.

Hypertensive disorders are a major complication of pregnancy and represent one of the leading causes of maternal and fetal morbidity and mortality (32). Hypertension is a multifactorial disease involving endothelial cells and leads to a variety of clinical symptoms including proteinuria and systemic inflammation (33). In a prospective case-control study, Patel et al. compared serum NGAL between three groups (mild preeclampsia, severe preeclampsia, and eclampsia) and controls. According to their results, NGAL levels significantly differed between the study groups, with highest values in eclamptic women, followed by those with severe and mild preeclampsia (34). In this study, we found higher serum levels of NGAL in women with severe preeclampsia compared to controls, although they did not reach 
statistical significance, and a significant correlation between serum NGAL and the levels of proteinuria in pre-eclamptic women (35). These findings support a possible implication of NGAL in hypertension-related inflammatory processes. As such, the higher urinary NGAL levels observed in infants with $\mathrm{MH}$ seem to indicate that hypertensive disorders of pregnancy might trigger a pro-inflammatory status not only in the mother, but also in the offspring. In support of this hypothesis, elevated pro-inflammatory molecules in the cord blood of neonates born by hypertensive mothers compared to normotensive ones have been previously reported (36).

Our data indicate that clinical factors other than GA may influence the early levels of renal biomarkers, including NGAL. As for sex, higher NGAL levels in females compared to males have been reported (17); in this study, females had slightly higher NGAL values at each of the three study evaluations. Regarding clinical antenatal and neonatal conditions potentially influencing renal biomarkers, a previous study on VLBW infants reported increased NGAL levels in the presence of culture-positive sepsis (37), suggesting a possible role for this biomarker in the prediction of late onset sepsis, given its rapid urinary excretion. However, we did not evaluate this point, since none of our infants developed sepsis during the period of evaluation.

The small sample size represents the main limitation of this study. Furthermore, given the low number of infants in the highest CRIB II classes, it was not possible to investigate the possible association between urinary biomarkers and CRIB score, an important predictor of mortality in preterm infants. Eventually, the disproportionate ratio in favour of males over females may have biased the power of the gender comparison that, differently from other studies, has led to non-significant results.

In conclusion, our data suggest the existence of a complex relationship between early renal biomarkers and antenatal, perinatal and post-natal characteristics in healthy preterm infants during the first week of life. Larger targeted studies are needed to validate these findings and to better clarify the physio-pathological mechanisms influencing renal biomarkers, in order to improve their predictive value on AKI detection in the premature neonatal population.

\section{Conflicts of Interest}

The Authors declare no conflicts of interest regarding this study.

\section{Authors' Contributions}

I.C., main protocol design and preparation of the manuscript; F.V., S.M., S.G., E.P. protocol design; F.Z., V.A. collection of specimens and data, contribution to manuscript preparation; C.D. laboratory assays, database update; M.C., laboratory assays, data collection, manuscript final revision; L.L., A.G. contribution to protocol design, statistical analysis; G.F., F.D.P., GLM, main supervisors.

\section{References}

1 Glover AV and Manuck TA: Screening for spontaneous preterm birth and resultant therapies to reduce neonatal morbidity and mortality: A review. Semin Fetal Neonatal Med 23(2): 126-132, 2018. PMID: 29229486. DOI: 10.1016/j.siny.2017.11.007

2 Schindler T, Koller-Smith L, Lui K, Bajuk B and Bolisetty S; New South Wales and Australian Capital Territory Neonatal Intensive Care Units' Data Collection: Causes of death in very preterm infants cared for in neonatal intensive care units: a population-based retrospective cohort study. BMC Pediatr 17(1): 59, 2017. PMID: 28222717. DOI: 10.1186/s12887-017-0810-3

3 Askenazi DJ, Griffin R, McGwin G, Carlo W and Ambalavanan $\mathrm{N}$ : Acute kidney injury is independently associated with mortality in very low birthweight infants: a matched case-control analysis. Pediatr Nephrol 24(5): 991-997, 2009. PMID: 19238451. DOI: 10.1007/s00467-009-1133-x

4 Abitbol CL and Rodriguez MM: The long-term renal and cardiovascular consequences of prematurity. Nat Rev Nephrol 8(5): 265-724, 2012. PMID: 22371245. DOI: 10.1038/nrneph.2012.38

5 Luyckx VA, Bertram JF, Brenner BM, Fall C, Hoy WE, Ozanne SE, Vikse BE: Effect of fetal and child health on kidney development and long-term risk of hypertension and kidney disease. Lancet 382(9888): 273-283, 2013. PMID: 23727166. DOI: $10.1016 / \mathrm{S} 0140-6736(13) 60311-6$

6 Kellum JA, Levin N, Bouman C and Lameire N: Developing a consensus classification system for acute renal failure. Curr Opin Crit Care 8(6): 509-514, 2002. PMID: 12454534. DOI: 10.1097/00075198-200212000-00005

7 Askenazi DJ, Ambalavanan N and Goldstein SL: Acute kidney injury in critically ill newborns: what do we know? What do we need to learn? Pediatr Nephrol 24(2): 265-274, 2009. PMID: 19082634. DOI: 10.1007/s00467-008-1060-2

8 Meisner A, Kerr KF, Thiessen-Philbrook H, Coca SG and Parikh $\mathrm{CR}$ : Methodological issues in current practice may lead to bias in the development of biomarker combinations for predicting acute kidney injury. Kidney Int 89(2): 429-438, 2016. PMID: 26398494. DOI: $10.1038 / \mathrm{ki} .2015 .283$

9 Kastl JT: Renal function in the fetus and neonate - the creatinine enigma. Semin Fetal Neonatal Med 22(2): 83-89, 2017. PMID: 28109705. DOI: 10.1016/j.siny.2016.12.002

10 Bonventre JV, Vaidya VS, Schmouder R, Feig P and Dieterle F: Next-generation biomarkers for detecting kidney toxicity. Nat Biotechnol 28(5): 436-440, 2010. PMID: 20458311. DOI: 10.1038/nbt0510-436

11 Hanna M, Brophy PD, Giannone PJ, Joshi MS, Bauer JA and RamachandraRao S: Early urinary biomarkers of acute kidney injury in preterm infants. Pediatr Res 80(2): 218-223, 2016. PMID: 27055185. DOI: 10.1038/pr.2016.70

12 La Manna G, Galletti S, Capelli I, Vandini S, Nisi K, Aquilano G, Mancini R, Carretta E, Montini G, Faldella G and Stefoni S: Urinary neutrophil gelatinase-associated lipocalin at birth predicts early renal function in very low birth weight infants. Pediatr Res 70(4): 379-383, 2011. PMID: 21691251. DOI: 10.1203/PDR.0b013e31822941c7

13 Fan H, Zhao Y, Sun M and Zhu JH: Urinary neutrophil gelatinase-associated lipocalin, kidney injury molecule-1, Nacetyl- $\beta$-D-glucosaminidase levels and mortality risk in septic patients with acute kidney injury. Arch Med Sci 14(6): 13811386, 2018. PMID: 30393493. DOI: 10.5114/aoms.2018.79006 
14 Peters H, Macke C, Mommsen P, Zeckey C, Clausen JD, Krettek $\mathrm{C}$, Neunaber $\mathrm{C}$ and Winkelmann $\mathrm{M}$ : Predictive value of osteoprotegerin and neutrophil gelatinase-associated lipocalin on multiple organ failure in multiple trauma. In Vivo 33(5): 15731580, 2019. PMID: 31471407. DOI: 10.21873/invivo.11639

15 Forster CS, Jackson E, Ma Q, Bennett M, Shah SS and Goldstein SL: Predictive ability of NGAL in identifying urinary tract infection in children with neurogenic bladders. Pediatr Nephrol 33(8): 13651374, 2018. PMID: 29532235. DOI: 10.1007/s00467-018-3936-0

16 Kukawczynska-Noczynska J, Suchanska R and BerghausenMazur M: Echocardiographic ultrasound screening assessment of the circulatory system of newborns delivered at basic level perinatal care centers. Adv Clin Exp Med 28(12): 1691-1695, 2019. PMID: 31851791 . DOI: $10.17219 / \mathrm{acem} / 110327$

17 Askenazi DJ, Montesanti A, Hundley H, Koralkar R, Pawar P, Shuaib F, Liwo A, Devarajan P and Ambalavanan N: Urine biomarkers predict acute kidney injury and mortality in very low birth weight infants. J Pediatr 159(6): 907-912.e1, 2011. PMID: 21784446. DOI: 10.1016/j.jpeds.2011.05.045

18 Saeidi B, Koralkar R, Griffin RL, Halloran B, Ambalavanan N and Askenazi DJ: Impact of gestational age, sex, and postnatal age on urine biomarkers in premature neonates. Pediatr Nephrol 30(11): 2037-2044, 2015. PMID: 2600170. DOI: 10.1007/ s00467-015-3129-z

19 Friedl A, Stoesz SP, Buckley P and Gould MN: Neutrophil gelatinase-associated lipocalin in normal and neoplastic human tissues. Cell type-specific pattern of expression. Histochem J 31(7): 433-441, 1999. PMID: 10475571. DOI: 10.1023/a:1003708808934

20 Nada A, Bonachea EM and Askenazi DJ: Acute kidney injury in the fetus and neonate. Semin Fetal Neonatal Med 22(2): 90-97, 2017. PMID: 28034548. DOI: 10.1016/j.siny.2016.12.001

21 ACOG Committee: Gestational hypertension and preeclampsia. Obstet Gynecol 133: e1-25, 2019. DOI: 10.1097/AOG.000000 0000003018

22 Ratiu D, Hide-Moser K, Morgenstern B, Gottschalk I, Eichler C, Ludwig S, Grüttner B, Mallmann $\mathrm{P}$ and Thangarajah F: Doppler indices and notching assessment of uterine artery between the 19th and 22nd week of pregnancy in the prediction of pregnancy outcome. In Vivo 33(6): 2199-2204, 2019. PMID: 31662556. DOI: 10.21873 /invivo.11722

23 Ezz-Eldin ZM, Hamid TA, Youssef MR and Nabil Hel-D: Clinical Risk Index for Babies (CRIB II) scoring system in prediction of mortality in premature babies. J Clin Diagn Res 9(6): SC08-11, 2015. PMID: 26266178. DOI: 10.7860/JCDR/ 2015/12248.6012

24 Frost BL, Modi BP, Jaksic T and Caplan MS: New medical and surgical insights into neonatal necrotizing enterocolitis: A review. JAMA Pediatr 171(1): 83-88, 2017. PMID: 27893069. DOI: $10.1001 /$ jamapediatrics.2016.2708

25 Cailes B, Kortsalioudaki C, Buttery J, Pattnayak S, Greenough A, Matthes J, Bedford Russell A, Kennea N and Heath PT; neonIN network: Epidemiology of UK neonatal infections: the neonIN infection surveillance network. Arch Dis Child Fetal Neonatal Ed 103(6): F547-F553, 2018. PMID: 29208666. DOI: 10.1136/archdischild-2017-313203

26 Argyri I, Xanthos T, Varsami M, Aroni F, Papalois A, Dontas I, Fanos V and Iacovidou N: The role of novel biomarkers in early diagnosis and prognosis of acute kidney injury in newborns. Am J Perinatol 30(5): 347-352, 2013. PMID: 23023560. DOI: $10.1055 / \mathrm{s}-0032-1326985$
27 Lavery AP, Meinzen-Derr JK, Anderson E, Ma Q, Bennett MR, Devarajan $\mathrm{P}$ and Schibler KR: Urinary NGAL in premature infants. Pediatr Res 64(4): 423-428, 2008. PMID: 18552711. DOI: 10.1203/PDR.0b013e318181b3b2

28 van Donge T, Welzel T, Atkinson A, van den Anker J and Pfister M: Age-dependent changes of kidney injury biomarkers in pediatrics. J Clin Pharmacol 59: S21-S32, 2019. PMID: 31502686. DOI: $10.1002 /$ jcph. 1487

29 DeFreitas MJ, Seeherunvong W, Katsoufis CP, RamachandraRao S, Duara S, Yasin S, Zilleruelo G, Rodriguez MM and Abitbol CL: Longitudinal patterns of urine biomarkers in infants across gestational ages. Pediatr Nephrol 31(7): 1179-1788, 2016. PMID: 26862052. DOI: 10.1007/s00467-016-3327-3

30 Tosse V, Pillekamp F, Verde P, Hadzik B, Sabir H, Mayatepek E and Hoehn T: Urinary NT-proBNP, NGAL, and H-FABP may predict hemodynamic relevance of patent ductus arteriosus in very low birth weight infants. Neonatology 101(4): 260-266, 2012. PMID: 22222353. DOI: 10.1159/000334826

31 Sellmer A, Bech BH, Bjerre JV, Schmidt MR, Hjortdal VE, Esberg G, Rittig S and Henriksen TB: Urinary Neutrophil Gelatinase-associated Lipocalin in the evaluation of Patent Ductus Arteriosus and AKI in Very Preterm Neonates: a cohort study. BMC Pediatr 17(1): 7, 2017. PMID: 28068947. DOI: 10.1186/s12887-016-0761-0

32 Hirshberg A and Srinivas SK: Epidemiology of maternal morbidity and mortality. Semin Perinatol 41(6): 332-337, 2017. PMID: 28823579. DOI: 10.1053/j.semperi.2017.07.007

33 Braunthal S and Brateanu A: Hypertension in pregnancy: Pathophysiology and treatment. SAGE Open Med 7: 2050312119843700, 2019. DOI: $10.1177 / 2050312119843700$

34 Patel M, Sachan R, Gangwar R, Sachan P and Natu S: Correlation of serum neutrophil gelatinase-associated lipocalin with acute kidney injury in hypertensive disorders of pregnancy. Int J Nephrol Renovasc Dis 6: 181-186, 2013. PMID: 24124387. DOI: $10.2147 /$ IJNRD.S45523

35 Simonazzi G, Capelli I, Curti A, Comai G, Rizzo N and La Manna G: Serum and urinary neutrophil gelatinase-associated lipocalin monitoring in normal pregnancy versus pregnancies complicated by pre-eclampsia. In Vivo 29(1): 117-121, 2015. PMID: 25600539.

36 Guillemette L, Lacroix M, Allard C, Patenaude J, Battista MC, Doyon M, Moreau J, Ménard J, Ardilouze JL, Perron P, Côté AM and Hivert MF: Preeclampsia is associated with an increased proinflammatory profile in newborns. J Reprod Immunol 112: 111114, 2015. PMID: 26454417. DOI: 10.1016/j.jri.2015.09.003

37 Parravicini E, Nemerofsky SL, Michelson KA, Huynh TK, Sise ME, Bateman DA, Lorenz JM and Barasch JM: Urinary neutrophil gelatinase-associated lipocalin is a promising biomarker for late onset culture-positive sepsis in very low birth weight infants. Pediatr Res 67(6): 636-640, 2010. PMID: 20496473. DOI: 10.1203/PDR.0b013e3181da75c1 